ERC Working Papers in Economics 14/08

July/ 2014

\title{
Does private tutoring increase students' academic performance? Evidence from Turkey
}

\author{
Giray Berberoğlu
}

Department of Secondary Mathematics and Science Education,

Middle East Technical University, Ankara, TURKEY

E-mail: giray@metu.edu.tr

\section{Aysit Tansel}

Department of Economics, Middle East Technical University, Ankara, TURKEY

Institute for the Study of Labor (IZA) Bonn, GERMANY

Economic Research Forum (ERF) Cairo, EGYPT

E-mail: atansel@ metu.edu.tr

Phone: + (90) 3122102073 


\title{
Does private tutoring increase students' academic performance? Evidence from
}

\section{Turkey}

\author{
Giray Berberoğlu
}

Faculty of Education, Department of Secondary Mathematics and Science Education, Middle East Technical University, 06800 Ankara, Turkey

e-mail: giray@metu.edu.tr

Aysit Tansel

Department of Economics, Middle East Technical University, 06800 Ankara, Turkey, Institute for the Study of Labor (IZA), Bonn, Germany and Economic Research Forum (ERF), Cairo, Egypt.

e-mail: atansel@metu.edu.tr

July 15,2014

\begin{abstract}
This paper investigates the effectiveness of private tutoring in Turkey. The authors introduce their study by providing some background information on the two major national examinations and three different kinds of tutoring. They then describe how they aimed to analyse whether attending private tutoring centres (PTCs) enhances Turkish students' academic performance. By way of multiple linear regression analysis, their study sought to evaluate whether the impact of private tutoring varies in different subject areas, taking into account several student-related characteristics such as family and academic backgrounds as well as interest in and perception of academic success. In terms of subject areas, the results indicate that while private tutoring does have a positive impact on academic performance in mathematics and Turkish language, this is not the case in natural sciences. However, as evidenced by the effect sizes, these impacts are rather small compared to the impacts of other variables such as interest in and perception of academic success, high school graduation fields of study, high school cumulative grade point average (CGPA), parental education and students' sociocultural background. While the authors point out that more research on the impact of further important variables needs to be done, their view is that school seems to be an important factor for determining students' academic performance.
\end{abstract}

Keywords Private tutoring, Academic Performance, Regression analysis, Turkey

JEL Codes: 120, 121, 122 


\section{Introduction}

Turkey is one of the countries where receiving private tutoring while preparing for national selection examinations is common. There are two major national examinations in Turkey. One is the national examination taken during the compulsory lower secondary education between grade levels 5 and 8 . The purpose of this examination is to select the students who will go to elite high schools such as science high schools, Anatolian high schools and private high schools. ${ }^{1}$ Students can prepare for this examination in various ways, including private tutoring. Performance in these examinations is important because being admitted to an elite high school increases a student's chances of subsequently entering an elite university and thus succeeding in the labour market. The second major national examination, which this paper focuses on, is the Higher Education Entrance Examination (HEEE). This highly competitive examination is taken by high school seniors or high school graduates to determine whether or not they enter a prestigious university and are thus well-positioned to qualify for a prestigious job later on. Students may start preparing for this examination in the first year of high school by way of private tutoring. However, preparations intensify especially during the last year of high school. ${ }^{2}$

There are three different forms of private tutoring in Turkey, which can be summarised ${ }^{3}$ as follows: The first is one-to-one individualised teaching delivered by either accomplished students of prestigious universities or retired or currently active teachers. It is the most expensive form of tutoring. Tutors often guarantee the success of their tutees and therefore charge high prices. The second kind of private tutoring is provided at the premises of regular schools by volunteer mainstream teachers for a nominal fee outside of formal class hours for

\footnotetext{
${ }^{1}$ There are several types of high schools in Turkey. Science high schools, for example, focus on subjects related to science, mathematics and technology Anatolian high schools teach some subjects through English (or sometimes German) as language of instruction. Private high schools, which are very competitive, charge high tuition fees.

${ }^{2}$, Students who constituted the sample of the present study started primary school when they were six years old. After five years of primary education and three years of lower secondary school (both of which are compulsory), 15-year-olds who wished to continue formal education entered high school (upper secondary), which they attended for four years (plus sometimes an extra year of language study). Higher education then consists of either four years at University, or two years at a Higher Vocational School.

${ }^{3}$ These three forms of private tutoring are reviewed in detail in Tansel and Bircan $(2006,2008)$ and Tansel (2013a).
} 
students who need help with their class work. School boards organise this form of private tutoring with the permission of the Turkish Ministry of National Education (MoNE). This form is common at primary school level but not at high school level.

The third and most prevalent form of private tutoring is provided by private tutoring centres (PTCs) known as "dershane" in Turkish. They are school-like organisations - with professional teachers - operating for profit. Public school teachers are prohibited from teaching at PTCs, which provide courses that supplement mainstream school subjects. However, their main activity centres on preparing students for the national examination for entry to elite high schools or for the national examination for entry to universities. They also provide counselling on the choice of universities, study fields and future career selection. Most PTCs administer initial placement tests to their applicants. Those students who do best on these tests are registered free of charge or with a reduced fee. Such students tend to score highly in the high school examination or HEEE. The success of these students is then used to advertise the effectiveness of that particular PTC's teaching. PTCs are licensed by the Ministry of National Education.

In Turkey, the HEEE system is centralised. Over time, because of the increase in the young population graduating from high schools and limited quotas in the university programmes, access to universities has become very competitive. In 2008, there were 1,574,928 applicants, only 505,083 of whom were selected and placed in the four- or two-year higher education programmes. The number of applicants increased to 1,800,433 in 2013. Only 877,784 of them were placed in four-year undergraduate programmes. Members of the remaining group either prepare for the HEEE again for the following year - mostly by attending PTCs, or look for a job to enter work life. Students who fail to attain placement in a university programme and give up, represent a population lacking the skills necessary for the labour market.

Access to a prestigious university programme is a major concern of parents and students. Despite 12 years of formal schooling, parents and students overrate the function of private tutoring which they see as the main solution for gaining access to a university. This thrust causes serious problems in mainstream educational practices. First, schools and school teachers lose their power and prestige in the society, as discussed by Doğan Kuban (2011). More value is given to PTCs and their teachers as evidenced by the questionnaire data provided by Turkish Educational Society, which carried out an investigation on the university entrance system in Turkey (TED 2005). Second, the teaching methodology used at PTCs is mainly geared towards practising exercises intended for memorising and remembering sample 
question formats and their answers (Gök 2010). Exercises on multiple-choice questions do not help conceptual learning among the students, thus in this respect PTCs threaten meaningful educational practices at schools. Finally, the private tutoring system creates further inequality by selecting the most successful students to train for the entrance examinations. As mentioned above, PTCs select their own students through an examination they conduct. In this way, they guarantee the success of the students at the HEEE to a great extent and secure a position in society as a prestigious PTC. On the other hand, this segregation also reflects different strata in terms of socioeconomic status, since prestigious PTCs charge even higher tuition fees which some parents are unlikely to be able to afford.

The system raises ethical concerns as well. The preparation process for the two national examinations disrupts formal school attendance, especially during the second semester of the senior years of primary schools and of the high schools. The students concentrate their efforts on the PTCs and on their own preparations rather than attending mainstream classes, providing expensive, false medical reports of sickness to account for their being absent from their mainstream classes. It has been argued that this undermines children's psychological and ethical development. Another point is that the national examinations do not cover all of the subjects taught at high school. Some subjects such as sports, arts, music and foreign languages are not given importance. In particular, high school students lack the expected foreign language skills. Moreover, the competitiveness of the examinations negatively reflects on social relations among students. Mutual trust and cooperation are impossible to cultivate among youngsters since their major objective is competing with others in the selection examinations.

With the overall increase in the number of primary and high school students in the educational system, the number of PTCs has also gone up. Within a nine-year period of time, from 1997 to 2006, the number of PTCs increased by 148 per cent, while the number of students receiving private tutoring increased by 198 per cent (TED 2005). During the academic year of 2010-2011, 1,234,738 primary and high school students were receiving private tutoring. There were 4,099 PTCs and 50,209 private tutors in Turkey (MoNE 2011). Parents' monetary investment in private tutoring in Turkey is another important issue. Parents spend more than 1.4 per cent of Turkey's GDP on private tutoring (Tansel and Bircan 2006). In 2005, per-student expenditure on the preparation for the HEEE through private tutoring was equivalent to USD 5,322 (TED 2005). These figures provide evidence of the importance, the function and the role of private tutoring within Turkish society. 


\section{Private tutoring and learning}

Private tutoring could be considered an out-of-school academic enterprise to enhance students' learning. Actually, the expectation is that if students spend more time on subject matter learning, they will eventually learn more and better and be successful in the national examinations, provided that the examinations cover basic aspects of the school curriculum. However, a few studies have examined the effect of private tutoring on students' academic performance by looking at the scores achieved in the national examinations. Some of this evidence has been reviewed by Mark Bray $(2006,2011)$. The results of these studies are inconclusive. Some of them found that students who received private tutoring had a better reading performance, less frequent grade repetition and a better academic performance in general, while other studies indicated no relationship between their performance and whether or not they had been privately tutored.

Several studies which analysed survey data indicated a positive impact of private tutoring on academic performance measured in terms of examination scores (Lavy and Schlosser 2005; Dang 2007; Banerjee et al. 2007). Other studies indicated either no impact or even a negative impact of private tutoring on academic performance (Suryadarma et al. 2006; Cheo and Quah 2005). In a third set of studies, the impact of private tutoring was found to be related to the fields of competence. For instance, Tran Thu Ha and Trudy Harpham (2005) reported that private tutoring has a positive impact on reading, but an insignificant effect on writing and numeracy. Similarly, Álvaro Choi et al. (2011) indicated that the impact is positive for mathematics and positive but decreasing for reading, but insignificant for the natural sciences. The inconsistent findings of these research studies might be partly due to methodological differences as well as differences in the respective cultural and institutional contexts of the countries studied.

In general, private tutoring is considered to be a serious problem in many countries, which has been extensively discussed by Bray et al. (2013). The only country for which a positive impact of PTCs on academic achievement was reported was Portugal (Mendes et al. 2013). Another analytic study was conducted by Simona Popa (2007) with private tutors in Romania. However, these studies do not attempt to answer the question of the impact of PTCs on academic performance measured in terms of the standardised national test scores.

Private tutoring and learning in Turkey 
The impact of private tutoring on academic achievement in Turkey has been pointed out and studied by several researchers. Aysit Tansel (2013b) discussed the negative impacts of private tutoring on equity in the Turkish educational system. Tansel and Bircan (2005) considered the students who took the HEEE in 2002 and analysed the university placement of those students who had attended private tutoring. Their findings indicate that attending PTCs does significantly increase both the test scores in most of the HEEE subjects and the probability of subsequent placement in a university programme. On the other hand, Berberoğlu (2010) and Berberoğlu et al. (2010) found no relation between private tutoring and academic achievement at primary education level. A report prepared by the Ministry of National Education (MoNE 2010) also indicated that the impact of private tutoring is related to the subject area. For instance, impact was small but positive in mathematics, but negative in Turkish language.

Students' belief about the positive impact of private tutoring is very common among the private tutoring attendees. The TED survey (TED 2005), mentioned earlier, asked for a comparison of the quality of teaching at PTCs and at mainstream schools. Responses showed that 44 per cent of the high school seniors, 65 per cent of the high school graduates, and 34 per cent of the university students believed that the quality of teaching was better at PTCs compared to mainstream schools. On the other hand, as Fatma Gök (2010) has pointed out, comparing performances among PTC students might increase learners' anxiety negatively and this would be detrimental to their success in the entrance examination, especially in the field of mathematics.

The major question at this point is whether or not private tutoring actually enhances students' academic performance in the examinations. This question is not easy to answer because of methodological issues involved in the analysis. One would need to compare two groups, students who attended private tutoring and students who did not, with both groups being otherwise equivalent in all other respects, i.e. their background such as high school branch and parental cultural and socioeconomic characteristics. It is this latter requirement which is impossible to fulfil. However, a possible way of analysing the impact of PTCs on academic performance in Turkish national examinations would be survey analysis with statistical control. Thus, in the study being presented here, we aimed to analyse whether attending PTCs enhanced the academic performance of our sample of Turkish students, and then to evaluate whether the impact was the same in different subject areas by considering several student-related characteristics. We used the students' HEEE test scores as the 
indicator of academic performance, since the content of the examination basically covers 12 years of national curriculum objectives. ${ }^{4}$

\section{The method}

In our study, we evaluated the impact of high school students' private tutoring on their academic performance in the HEEE by using a multiple linear regression analysis. In the multiple regression method, a dependent variable is predicted by a set of independent variables, named as predictors (Stevens 1992). This analysis provides the R-squared measure, which is the proportion of the total variation of the dependent variable that is accounted by the set of predictors. Similarly, the contribution of each independent variable is also studied by the b-constant, which is named as un-standardised regression coefficient. These coefficients indicate the change in the dependent variable with one unit change in the independent variable holding all other variables constant (Tabachnick and Fidell 1996). Thus, evaluating R-squared gives the linear contribution of all the predictor variables in the regression equation on the variance of the dependent variable, while, on the other hand, evaluating b-constant indicates the unique contribution of each predictor variable on the dependent variable. The dependent variable is the raw test scores total number of correct responses - in the various subtests such as Turkish language, mathematics and natural sciences in the HEEE.

The HEEE is prepared and administered by the Student Selection and Placement Center (SSPC) and includes multiple-choice items only, which are scored as 0 or 1 (wrong or correct answer, respectively). The raw scores represent the total number of correct answers given by the students in each subtest considered in the regression analysis. Thus, in our study, the impact of private tutoring on academic performance was interpreted in terms of number of items correctly answered by the students. This score, expressed as the students' academic performance, was treated separately for the subscales used in the HEEE. The details of the predictors used in the regression analysis are provided in the "Regression results" section below.

\footnotetext{
${ }^{4}$ The Turkish Higher Education Entrance Examination (HEEE) is held every year in early summer in two stages. To pass the first stage, high school graduates have to answer 160 multiple-choice questions in 160 minutes. The exam form includes four subjects, namely Turkish, social sciences, mathematics and natural sciences as separate subtests. Students who pass this exam take the second-stage exam, by choosing among five tests in different subject areas depending on their aptitude and the subject areas they are hoping to study at university. Each test has different number of items in multiple-choice format and is subject to a different time span for completion. Students who fail this exam, they can repeat it the following year.
} 
Instruments

In our study, we used two instruments. The first included the HEEE subtests designed by the SSPC. The second instrument was the Student Questionnaire developed by the SSPC. This questionnaire was basically designed to collect information about the students, their family background and school characteristics. This questionnaire was constructed explicitly for our research. It was administered in two consecutive years of 2007 and 2008. The results obtained in the first administration were used for piloting purposes. The questions were revised for the main study. The main survey was administered in the year of 2008 via the Internet.

In the questionnaire, there are questions about the student's parental educational level, the student's interests in different fields of study, the student's perception of his or her academic potential in different disciplines, and whether he or she received private tutoring during their high school years. Our study's main focus was on private tutoring for the HEEE. Thus, the question about the duration of private tutoring was designed to collect information about those students who received private tutoring exclusively for the purpose of preparing for the HEEE. Moreover, private tutoring institutions provide at least a year of education for the examinees if it is for the HEEE. On the other hand, students may start going for private tutoring from the early years of their high school education. Our specific question asked for how long students had received private tutoring for the HEEE. The response categories were none, one year, two years and three years or more. In our analysis, we reduced these four categories to a dichotomy (either no private tutoring or private tutoring for $1+$ year[s]), since the number of students who received private tutoring for more than one year was very low.

We constituted the dimensions of our questionnaire through the exploratory factor analysis method. Factor analysis is a technique to reduce the number of variables in a research based on the correlations among them. In the questionnaire data, factor analysis was carried out for the purpose of grouping the questionnaire items. The items which were grouped together created the dimensions of the questionnaire. Some of the dimensions used in the present analysis were defined as index values. These index values had 0 mean and 1 standard deviation. Any value above 0 meant a level which was above the mean of the sample. Inversely, any value below 0 meant a level which was below the mean of the sample. Cronbach's alpha reliability coefficients obtained on the HEEE verbal and quantitative sections scores were 0.97 and 0.93 , respectively. Cronbach's alpha reliability coefficient obtained on the scores of the Student Questionnaire is reported as 0.95 in the sample. These 
coefficients indicate that students consistently filled out the items in the verbal and quantitative test batteries and the Student Questionnaire.

Our Student Questionnaire was posted on the website of the SSPC, and students were encouraged to fill it in electronically online before they completed their application forms for the entrance examination. As a result, the questionnaire was filled in on a voluntary basis during the application period. Table 1 shows the number of students who participated in the study with respect to their subject combination tracks at high school. There are a total of 9,983 observations in our sample. Most of these observations come from the mathematicsnatural sciences tracks. The least number of observations is in the field of social sciences. This reflects the distribution of students' subject choices in Turkish high schools.

Table 1 The sample of the study

\begin{tabular}{|l|l|}
\hline $\begin{array}{l}\text { Subject combination } \\
\text { track }\end{array}$ & Number of students \\
\hline $\begin{array}{l}\text { Mathematics- } \\
\text { natural sciences }\end{array}$ & 3,227 \\
\hline $\begin{array}{l}\text { Turkish language-- } \\
\text { mathematics }\end{array}$ & 3,118 \\
\hline Social sciences & 1,332 \\
\hline Other & 2,306 \\
\hline Total & $\mathbf{9 , 9 8 3}$ \\
\hline
\end{tabular}

The Higher Education Entrance Examinations (HEEE) in Turkey

There are four major subject combination tracks at high schools in Turkey. These are mathematics-natural sciences, Turkish-mathematics, Turkish-social sciences, and languages. Students choose one of these tracks during their high school years, based on their interests, future plans and their Grade Point Average (GPA) in the courses of the different tracks. These students take the HEEE at the end of the 12th grade. In our study, we investigated three subject combination tracks: mathematics-natural sciences, Turkish-mathematics and Turkish-social sciences. Mathematics-natural sciences and Turkish-mathematics were the most popular tracks among the students, because of the confirmed success of students from these fields in the HEEE. Thus, graduates of these tracks constituted the majority of the population of interest in our study. Those students who received private tutoring basically came from mathematics-natural sciences and Turkish-mathematics tracks. Students in the language track took foreign language tests in English, German or French. The score criterion 
changed in line with the tests the language students took. Thus we did not consider language tracks and foreign language tests in our analysis.

As already mentioned in footnote 4, the HEEE consists of two stages. The first stage is designed to assess students' ability to use knowledge of basic concepts and principles within the framework of primary and high school curricula, whereas the second stage is designed to assess students' achievement related to high school curriculum objectives in different fields of study. Both stages have similar subtests, such as Turkish language, social sciences, mathematics and natural sciences. The subtests have multiple-choice items with five alternatives. All students are expected to respond to all of the subtests in the first stage. In the second stage, students respond to different subtests depending on their respective high school subject combination tracks. This choice is also influenced by the requirements of the university programmes they want to attend.

Students who take the HEEE answer the test items selectively. For instance, students from mathematics-natural sciences and Turkish-mathematics tracks strive to answer as many items as possible in the mathematics subtests. They therefore attend private tutoring in order to achieve their best performance in this particular subtest. We also included the Turkish language subtests in our regression analysis, since in the first stage this test must be taken by all students, while in the second stage it is taken only by students majoring in social sciences and languages.

Variables in the regression

In our regression analysis, we used family background characteristics and student-related factors as predictor variables besides a dummy variable for students who received private tutoring and students who did not receive any private tutoring during their high school years. Our selection of predictor variables was carried out in accordance with the major findings of other researchers. For instance, students who are more interested in mathematics and related subjects are more successful on the large-scale testing programmes such as the Programme for International Student Assessment (PISA) (Ferry et al. 2000; OECD 2004). Similarly, if students believe that they are successful and feel confident in different subject matter areas, they tend to have higher achievement level than the ones who have less confidence. This issue is extensively considered in the literature under the titles of "self-efficacy" and "academic self concepts". They are psychological constructs to explain the students' perception about themselves for succeeding in various subject areas, especially in mathematics and the natural 
sciences (Cooper and Robinson 1991; Meece et al.1990; Ferry et al.2000; Hackett and Betz 1989; Hall and Ponton 2005; O’Brien et al. 1999; Abu-Hilal 2000; Marsh1986). Thus, in our own study, we considered students' interests and perception of academic success in different subject matter areas in the regression analysis based on the content of the questionnaire items (Marsh 1986; Meece et al. 1990; Ferry et al. 2000).

Students attempt to solve those items in the tests which match their graduation fields, thus, they are selective in their choice which subtests they answer. This makes the subject combination track one of the most important factors in determining their performance in the examination. Moreover, receiving private tutoring also seems to be related to students' choice of track. For instance, in the sample of our study, 85 per cent of the students in the mathematics-natural sciences track received private tutoring, 71 per cent in Turkishmathematics, and 53 per cent in social sciences. Thus a comparison of the academic performance of the students who received private tutoring with the students who did not receive private tutoring would have been a comparison between non-equivalent groups. Moreover, these students were taught within different high school curricula in mathematics and natural science courses. In order to make the comparison fairer, the student's subject combination track had to be controlled for, so we considered it as a dummy in our regression analysis. Out of the three subject combination tracks in our sample (mathematics-natural sciences, Turkish-mathematics and social sciences), we coded two dummy variables. Field 1 represents mathematics-natural sciences versus the others, and Field 2 represents Turkishmathematics versus the others in the regression analysis.

It is well known that academic performance is highly related to the student's parental, cultural and socioeconomic characteristics. In the literature on private tutoring, this issue is frequently discussed as one of the inequalities which private tutoring creates (Bray et al. 2013). In Turkey, the majority of the students receive private tutoring, regardless of their parental, cultural and socioeconomic background. Because of the high demand for university education, most parents strive to send their children to PTCs. On the other hand, students who do not receive private tutoring are likely to have a low cultural and socioeconomic background. We therefore had to take into account a possible variation in terms of parental background characteristics among the students in the cohort of our study by making these characteristics one of the predictor variables in our regression analysis as well.

Finally, we used receiving private tutoring as an additional dummy variable. Our questionnaire asked whether the student took a year or more of private tutoring for the HEEE. Some students start taking private tutoring at grade level 9. Others start at later grades. Since 
the question limited the answer to the HEEE, if a student answered "never" that meant he/she did not receive any private tutoring for the HEEE. In this coding, 1 represented students who received private tutoring for the HEEE for a year or more, and 0 represented students who did not receive any private tutoring for the HEEE. As explained before, students receive private tutoring for the HEEEs for at least a year. Thus, this dichotomy clearly differentiates between students who received at least a year of private tutoring for the HEEEs and those who received none at all. In our sample, 68 per cent of the students received private tutoring during their high school education for the HEEE.

Parental educational and cultural and socioeconomic level was used as an index value. This index includes parents' education level, the number of books at home, whether parents bought a daily newspaper, whether their children attended pre-school education, and the possession of a separate room for the children. This index has a Cronbach's alpha reliability of 0.70. Two separate indexes were also used for the student's interests and perception of success in various subject areas such as mathematics and natural science, and Turkish language. The former index was used in predicting the raw scores of mathematics and natural science subtests, the latter one was used in predicting the raw scores in Turkish subtests. These indexes reflect how much students are interested in related subjects and to what extent they feel they are successful in these subjects. These indexes have Cronbach's alpha reliabilities of 0.88 and 0.79 respectively. Another explanatory variable we used was the students' cumulative grade point averages (CGPA) at high school graduation. CGPA is defined by the SSPC as a T score with the mean of 50 and standard deviation of 10 . The independent variables were all collected by way of a self-reported questionnaire. Parental educational and cultural and socioeconomic level, students' high school branch and questions about PTC attendance all depend on students' responses on a set of questions. Interest and perception of success were also defined by the students' responses on the questionnaire items which were designed on five-point scale. Students were asked how much they were interested in different subject matter areas and to what extent they felt successful in these areas with the alternatives of "Not at all", "Very little", "Little", "Much" and "Very much".

We then compared the students who received private tutoring with the students who did not receive private tutoring with respect to their various characteristics. There are differences between the two groups with respect to the variables explained above. For instance, students who did not receive private tutoring come from lower cultural and socioeconomic environments. This is evidenced by the index value. Index values are z-scores, where 0 stands for the mean of the sample studied. As it goes up to positive values, it means that cultural and 
socioeconomic status increase. If it goes down to negative values, they decrease. Students who did not receive private tutoring had a mean of -0.45 , while students who did receive private tutoring had a mean of +0.31 . This confirms non-equivalence of the two groups compared in terms of parental background characteristics since positive index values were obtained for those students who attended private tutoring and came from more educated families and better cultural environments. Similarly, for the CGPA, students who received private tutoring had a mean of 75.25 and students who did not receive private tutoring had a mean of 71.82 as defined by the standard $\mathrm{T}$ score. This confirms that students who received private tutoring did have more academic success at school. Students' interest in and perception of success in Turkish language and social sciences courses are more or less the same between the two groups. However, the interest in and perception of success in mathematics and natural science courses differ between the two groups, with the mean index value scores for students who did receive private tutoring being higher $(+0.22)$ than for students who received none $(-0.22)$. Therefore, we can say that those students who received private tutoring had a higher interest in academic subjects and higher perceptions of their academic success.

Considering the general findings summarised above, it is clear that receiving private tutoring is common among the students enrolled in mathematics-natural sciences and Turkish-mathematics tracks compared to students enrolled in other subject areas, such as social sciences. Moreover, students who received private tutoring are the ones with greater interest in and academic confidence in the natural science and mathematics fields, and they have a higher cultural and socioeconomic status than students who did not have any private tutoring. Further, students attending private tutoring have higher high school academic success.

These findings clearly indicate that the direct comparison of the means of the scores in the sub-dimensions of HEEE is not a suitable way of comparing the two groups, since there are confounding variables, which make the groups being compared non-equivalent. Thus, a regression analysis was likely to provide a better comparison since all the predictor variables in the equation would control each other, and non-equivalence of the groups would be statistically controlled for. 


\section{The regression results}

In this paper our dependent variable is academic performance as depicted by the raw scores obtained in the subtests of the HEEE. Our independent variables were: interest in and perception of success, parents' educational and cultural background, student's high school tracks, student's high school CGPA and receiving at least one year of private tutoring for the HEEE. Table 2 shows the R-squared changes which enabled us to assess the importance of the explanatory variables on the examination performance. The R-squared change needs to be interpreted so as to compare the magnitude of the explained variance on the dependent variable by each of the independent variables. Another way of comparing the relative impact of the independent variables is using the effect size values. They indicate practical significance of the contribution of each variable in the regression equation on the dependent variable. In the regression analysis, the squared value of the partial correlation coefficients can be used with the criterion values of $0.02,0.13$ and 0.26 for small, medium and large effect sizes respectively (Cohen 1988).

We carried out the six stepwise regression analyses to assess the impact of receiving private tutoring on the academic performance of students in the Turkish language, mathematics and natural science subtests of the first and the second sections of the HEEE. Table 2 indicates the summary results of these six regression analyses. The table shows the explanatory variables entered in the regression equation and their contribution to explaining the amount of variance of the dependent variables (raw subtest scores). In the overall models, the amount of total variance explained by the combination of the explanatory variables is also provided in Table 2 . 
Table 2 R-squared and R-squared change values of the predictor variables

\begin{tabular}{|c|c|c|c|c|c|c|c|}
\hline & R-squared & Change & & & & & \multirow{2}{*}{$\begin{array}{l}\mathrm{R}- \\
\text { squared }\end{array}$} \\
\hline Subtest & $\begin{array}{l}\text { Interest- } \\
\text { Perception }\end{array}$ & Parental & CGPA & Field 1 & Field 2 & Tutoring & \\
\hline Turkish-1* & 0.085 & 0.043 & 0.098 & 0.002 & 0.026 & 0.018 & 0.27 \\
\hline Turkish-2 & 0.032 & 0.001 & 0.001 & 0.070 & 0.357 & 0.002 & 0.46 \\
\hline Maths-1 & 0.411 & 0.005 & 0.052 & 0.055 & 0.111 & 0.010 & 0.64 \\
\hline Maths-2 & 0.026 & 0.015 & 0.067 & 0.310 & 0.093 & 0.001 & 0.51 \\
\hline $\begin{array}{l}\text { Natural } \\
\text {.Science-1 }\end{array}$ & 0.061 & 0.007 & 0.015 & 0.615 & 0.023 & 0.000 & 0.72 \\
\hline $\begin{array}{l}\text { Natural } \\
\text {.Science-2 }\end{array}$ & 0.010 & 0.012 & 0.026 & 0.500 & 0.001 & - & 0.55 \\
\hline
\end{tabular}

*1 and 2 stands for the respective subtest in the first and second stage of HEEE.

Table 2 shows that the impact of receiving private tutoring on the subtest scores is significant except for the natural science subtests, but small in comparison to the impact of the other explanatory variables. The total amount of variance explained in the raw test scores changes between 27 per cent and 72 per cent.

The contribution of the explanatory variables on the dependent variables changes from one subtest to another. The impacts of interest in and perception of success in the first section subtests are rather large. On the other hand, the fields of study (subject combination tracks) seem to be the most important variable in the analyses. The greatest impact of receiving private tutoring is observed in the Turkish-1 subtest. However, this impact is only 1.8 per cent, which is rather small in explaining the performance of students in the HEEE.

Table 3 indicates the $b$ constants, their $t$ value and the significance levels for the regression equations.

Table 3 Regression (b) constants, their T-values and significant levels

\begin{tabular}{lllllll}
\hline & Turkish 1 & Turkish 2 & Maths 1 & Maths 2 & $\begin{array}{l}\text { Natural } \\
\text { Science 1 }\end{array}$ & $\begin{array}{l}\text { Natural } \\
\text { Science 2 }\end{array}$ \\
\hline Interest- & 1.433 & 0.893 & 3.745 & 1.642 & 2.740 & 0.851 \\
perception & 23.943 & 10.239 & 46.970 & 19.112 & 35.557 & 11.321 \\
& $(0.000)$ & $(0.000)$ & $(0.000)$ & $(0.000)$ & $(0.000)$ & $(0.000)$ \\
\hline Parental & 0.988 & - & 1.094 & 0.943 & 0.767 & 0.669 \\
& 15.659 & & 17.019 & 13.610 & 13.221 & 11.816 \\
& $(0.000)$ & & $(0.000)$ & $(0.000)$ & $(0.000)$ & $(0.000)$ \\
\hline CGPA & 0.135 & 0.025 & 0.162 & 0.137 & 0.092 & 0.080 \\
& 26.880 & 3.426 & 31.093 & 24.341 & 18.236 & 16.151 \\
& $(0.007)$ & $(0.001)$ & $(0.000)$ & $(0.000)$ & $(0.000)$ & $(0.000)$ \\
\hline
\end{tabular}




\begin{tabular}{lllllll}
\hline Field 1 & 0.402 & -6.148 & 6.597 & 8.342 & 9.190 & 8.539 \\
& 2.711 & -28.490 & 35.661 & 41.845 & 51.739 & 49.260 \\
& $(0.007)$ & $(0.000)$ & $(0.000)$ & $(0.000)$ & $(0.000)$ & $(0.000)$ \\
\hline Field 2 & 2.186 & 8.794 & 5.781 & 5.124 & -3.461 & -0.493 \\
& 15.069 & 41.545 & 39.192 & 32.593 & -24.684 & -3.601 \\
& $(0.000)$ & $(0.000)$ & $(0.000)$ & $(0.000)$ & $(0.000)$ & $(0.000)$ \\
\hline Tutoring & 1.257 & 0.937 & 0.974 & 0.362 & - & - \\
& 8.917 & 4.875 & 6.786 & 2.339 & & \\
& $(0.000)$ & $(0.000)$ & $(0.000)$ & $(0.019)$ & & -4.998 \\
\hline Constant & 9.761 & 4.787 & -3.344 & -8.837 & -1.370 & - \\
\hline
\end{tabular}

Interest-perception: How students feel confident in different subject matter areas and demonstrate interest in the related field.

Parental: The level of education of the parents, number of books at home, whether daily newspaper is bought, whether children attended preschool education and possession of separate room at home for the children.

CGPA: Cumulative Grade Point Averages in high school.

Field 1: Mathematics-natural sciences versus other fields of study (subject combination tracks).

Filed 2: Turkish-mathematics versus other fields of study.

Tutoring: Receiving at least one year or more private tutoring versus having no private tutoring for the university entrance examinations.

R squared: Amount of variation explained on the raw scores of respective subtest scores.

When the estimates in the regression equations are considered, the impact of each independent variable on the dependent variable can be clearly seen. In the regression analysis, coefficient estimates indicate the change in the dependent variable with one unit change in the independent variable when all the other variables in the regression equation are kept constant (Tabachnick and Fidell 1996). For instance, in the mathematics-1 subtest, receiving private tutoring creates an expected increase of 0.974 points in the mathematics- 1 raw test scores. Similarly, in the Turkish language-1 subtest, the expected increase on the respective subtest score is 1.257 . These values clearly indicate that the impact of tutoring on students' performance in the HEEE is rather small. On the other hand, the impacts of the other independent variables are larger than the impact of the private tutoring. For instance, for those students who graduated in the mathematics-natural sciences track, the expected increase in the natural science-2 subtest score is 9.19. Since the raw scores are defined as the total number of correct responses, receiving private tutoring results in solving an additional nine questions correctly in the natural science-2 subtest when all other factors are held constant. Similarly, for the graduates of the Turkish-mathematics track, the expected change in the number of correct responses is 8.794 in the Turkish language- 2 subtest.

In the regression analyses, we found all the squared partial correlations to be below the criterion of small effect size of 0.02 for the private tutoring variable. The greatest effect size was observed for the Turkish-1 subtest, which is 0.014 . 
To sum up, we found students who were interested and felt successful in their respective tracks, who graduated from high school with a relatively high CGPA, who completed their education in a track which was compatible with the higher education programme they wanted to pursue and came from high cultural and socioeconomic environments have been more likely to succeed in the HEEEs. When compared to these factors, receiving private tutoring, is significant, but explains only a small amount of variation in some of the test scores.

\section{Conclusion}

This paper evaluates the relationship between receiving private tutoring and academic performance in Turkey. Academic performance is defined as the scores achieved in the national university selection examination (HEEE). We began by examining the main characteristics of the private tutoring system. Next, we investigated whether private tutoring enhances the learning of students for access to university. We considered two groups of students; those who received at least a year of private tutoring and those who did not receive any tutoring at all. We did this by quantifying the responses of university candidates on a questionnaire prepared and administered by the SSPC in Turkey. To our knowledge this is the first study which includes variables such as the students' interest in various subjects (in our sample we included mathematics, natural sciences and Turkish language) and students' selfconfidence in these subjects while investigating the academic performance in the HEEE. Our inclusion of these factors may have contributed to the result of a somewhat smaller relationship between attending PTCs and academic performance than common belief might have expected.

Our results indicate that while private tutoring does have a positive and statistically significant impact in fields of competence such as mathematics and Turkish language, this is not the case in the natural sciences. In this respect, the results of the present study are consistent with those of an earlier study carried out in Turkey on the 2002 HEEE (Tansel and Bircan 2005). However, in our present study, these impacts are small compared to the impacts of other variables such as student's interest and perception of academic success in different subject areas, high school graduation tracks, high school CGPA and parents' cultural and socioeconomic status. The findings of our present study have several implications. First, there is an inequality between students who receive private tutoring and the ones who do not.

Private tutoring is more common among children whose parents have high education levels. This strengthens the idea of social inequality which private tutoring fosters in the society. 
Most likely, such parents have more economic power to send their children for private tutoring compared to those who do not send their children for private tutoring.

Students with a high level of interest in various subjects such as mathematics, natural science and Turkish language who are also more confident of their success in these respective subjects are more likely to receive private tutoring. They are also the ones with higher CGPA at high school. One may argue that a student's interest in various subjects and their academic confidence of success in these subjects may partly be developed through the education they receive in the PTCs. Students choose their subject combination tracks in the early years of high school based on their interests and on the grades they receive in various subject areas. Thus, it is not wrong to claim that the development of a positive interest in various subjects and higher academic confidence in oneself is in fact more likely to occur during the formal school years than at the PTCs.

As was pointed out before, the empirical findings of this study support the findings of existing literature where the positive, albeit small impact of private tutoring seems consistent with similar studies in other countries (Lavy and Schlosser 2005; Dang 2007; Banerjee et al. 2007). Another result which is consistent with related literature is the impact of private tutoring across different tracks. We found positive impacts in Turkish language and mathematics subtests. However, we found no impact in the natural science subtests. This is similar with the finding reported by Choi et al. (2011) with reference to South Korea. Among the variables we considered in our regression analysis, the students' track during their high school education explained more variance in the subtest scores in HEEE than receiving private tutoring. Thus, we can conclude that the high school curriculum students are exposed to is more important than receiving private tutoring in determining the success at the HEEE. On the other hand, this creates an inequality in terms of subject combination tracks. For equity purposes, the results of our study suggest that there should be one common curriculum for all the students. As a policy implication, the government should consider providing equal opportunities for all students at high school level by implementing the same curriculum for everyone.

Furthermore, students' interest in and perception of success in various subjects and their academic success during their high school years are important determinants of their performance in the HEEE. These variables might be considered as the school-related factors. Meanwhile, parents' cultural and socioeconomic status is an other important determinant of the success at the HEEE. The positive impact of parental factors on the examination performance has been found by many researchers in a variety of contexts. These particular 
student-related factors may also have indirect impacts on students' interest and academic confidence in various subject matter areas as well.

The significant but small contribution of PTCs is somewhat contradicts the findings of earlier research studies reported in related literature. There could be several reasons of this contradiction. First of all, in our present study, student-related factors were controlled for somewhat differently than in earlier studies. For instance, unlike existing studies, our study considered students' interest in different subject matter areas and their perception of success as one of the predictor factors in the model. Other studies which report significant and important effects of PTCs do not consider this major variable in their analysis. Second, in our present study, the type of educational practices pursued by the PTCs were not considered. As is well known and as we clearly articulated before, the teaching methodology used in the PTCs in Turkey is to basically practise with multiple-choice test questions (Gök 2010). There is less emphasis on conceptual understanding but rather, the major criterion of success is the number of test questions correctly solved by the students in a day. There is a belief that the more multiple-choice questions students are exposed to the more likely they are to be successful in the HEEE. This is in theory not a proper way of teaching, and likely to hinder the effect of PTCs in the national examinations. However, throughout the years, this practice has become even more important at the PTCs. The PTCs usually advertise their institutions based on the number of multiple-choice questions they provide for their students to work on. This could be one of the major reasons for the significant but small impact of PTC attendance among the students on their HEEE results. Solving one or two multiple-choice questions could be considered within the chance level, but can change the HEEE scores of the students dramatically.

As it was reported in the introduction of this paper, parents spend in excess of USD 5000 per year to have their children solve mostly one or two more multiple-choice questions in the national examination. It seems a waste of money, since this expenditure goes to the private sector rather than to formal schooling. It would seem that educational outcomes are likely to be much better if parents financially supported formal schooling rather than PTCs.

In our present study, we found two important general factors to be the most important determinants of students' success in passing the HEEE. The first one concerns student-related factors, such as family background characteristics and interest in and perception of success in various subject matter areas. These two variables might even be interrelated as well. The second concerns school-related factors, including student's subject combination tracks and academic success as defined by their grade point averages. Unlike other studies, the main 
characteristic of our study is to take both student-related and school-related factors into consideration while investigating the impact of private tutoring on the success in national university examinations. Studying the impact of private tutoring is a somewhat complicated issue, since there are many factors and variables involved which might influence academic success. This study has made a unique start in considering some of the very important factors in its analysis. However, to obtain an even clearer picture of the interplay of all the aspects involved in the effectiveness of private tutoring, further studies are required in this field in different cultural settings by considering some other important variables which can be grouped under either student-related or school related factors.

\section{References}

Abu-Hilal, M. M. (2000). A structural model for predicting mathematics achievement: Its relation with anxiety and self-concept in mathematics. Psychological Reports, 86(3). 835-847.

Gök, F. (2010). Marketing hope: Private institutions preparing students for the university entrance examination in Turkey, In S. K. Amos (ed.), International educational governance, international perspectives on education and society (pp. 123-13). International Perspectives on Education and Society series, vol. 12. Bingley, UK: Emerald.

Banerjee, A.V., Cole. S., Duflo, E. \& Linden. L. (2007). Remedying education: Evidence from two randomized experiments in India. Quarterly Journal of Economics, 122 (3), $1235-1264$.

Berberoğlu,G., Demirtaşlı, N., İş Güzel, C., Arıkan, S. \& Özgen Tuncer, C. (2010). Okul Dışı Etmenlerin Öğrenci Başarısı ile İlişkisi [Effects of out-of-school factors on students' achievement]. Cito Ë̆itim: Kuram ve Uygulama. 1(7), 28-38.

Berberoğlu, G. (2010). Ölçme ve Değerlendirmenin Uygulamaya Yansıyan Boyutları [Dimensions of measurement and evaluation which are reflected to educational practices]. Cito Eğitim: Kuram ve Uygulama, 1(10), 10-14.

Bray, M. (2006). Private supplementary tutoring: Comparative perspectives on patterns and implications, Compare: A Journal of Comparative Education, 36(4), 515-530.

Bray, M. (2011). Does tutoring work? In M. Bray, The challenge of shadow education: Private tutoring and its implications for policy makers in the European Union (pp. 4751). Brussels: European Commission. Accessed 5 December 2012 from http://www.nesse.fr/nesse/activities/reports/the-challenge-of-shadow-education-1.

Bray, M., Mazawi, A. E. \& Sultana, R. G. (2013). Private tutoring across the Mediterranean: Power dynamics and implications for learning and equity. Rotterdam: Sense Publishers.

Briggs, D. C. (2001). The effect of admissions test preparation: Evidence from NELS: 88, Chance, 14(1), 10-18.

Buchmann, C. (2002). Getting ahead in Kenya: Social capital, shadow education, and achievement. In E. Hannum (ed.) Schooling and social capital in diverse cultures (pp.133-159). Research in the Sociology of Education series, Volume 13. Bingley, UK: Emerald. 
Cheo, R., \& Quah, E. (2005). Mothers, maids and tutors: An empirical evaluation of their effect on children's academic grades in Singapore. Education Economics, 13(3), 269 285.

Choi, A., Calero., J. \& Escardíbul, J.-O. (2011). Hell to touch the sky? Private tutoring and academic achievement in Korea. IEB Working Paper series No. 2011/10. Barcelona: Barcelona Institute of Economics (IEB).

Cooper, S. E. \& Robinson, D. A. G. (1991). The relationship of mathematics self efficacy beliefs to mathematics anxiety and performance. Measurement \& Evaluation in Counseling \& Development, 24(1), 4-11.

Cohen, J. (1988). Statistical power analysis for the behavioral sciences (2nd edn). Hillsdale, NJ: Lawrence Erlbaum Associates.

Dang, H.-A. (2007). The Determinants and Impact of Private Tutoring Classes in Vietnam, Economics of Education Review, 26(6), 684-699.

Ferry, T. R., Fouad, N. A. \& Smith, P. L. (2000). The role of family context in a social cognitive model for career-related choice behavior: A math and science perspective. Journal of Vocational Behavior, 57(3), 348-364.

Gök, F. (2010). Marketing hope: Private institutions preparing students for the university entrance examination in Turkey. In S. K. Amos (ed.), International educational governance, international perspectives on education and society (pp. 123-134). International Perspectives on Education and Society series, vol. 12. Bingley, UK: Emerald.

Ha, T. T. \& Harpham, T. (2005). Primary education in Vietnam: extra classes and outcomes. International Education Journal, 6 (5), 626-634.

Hackett, G. \& Betz, N. E. (1989). An exploration of the mathematics self-efficacy mathematics performance correspondence. Journal for Research in Mathematics Education, 20(3), 261-273.

Hall, J. M. \& Ponton, M. K. (2005). Mathematics self-efficacy of college freshman. Journal of Developmental Education, 28(3), 26-33.

Kuban, D. (2011). Dersane mi Istersiniz, Öğretim mi? [Would you like private tutoring or teaching?] Cumhuriyet Bilim Teknik, 1282(2), 14 October.

Lavy, V. \& Schlosser, A. (2005). Targeted remedial education for underperforming teenagers: Costs and Benefits. Journal of Labor Economics, 23(4), 839-74.

Lee, J-T., Kim, Y.-B. \& Yoon, C.-H. (2004). The effects of pre-class tutoring on student achievement: challenges and implications for public education in Korea. KEDI Journal of Educational Policy, 1(1), 25-42.

Marsh, H. W. (1986). Verbal and math self-concepts: An internal/external frame of reference model. American Educational Research Journal, 23(1), 129-149.

Meece, J. L., Wigfield, A. \& Eccles, J. S., (1990). Predictors of mathematics anxiety and its influence on young adolescents' course enrollment intentions and performance in mathematics. Journal of Educational Psychology, 82(1), 60-70.

Mendes, A., Costa, J. A., Ventura, A., Azevedo, S. \& Gouveia, A. (2013). Private tutoring in Portugal: Patterns and impact at different levels of education. In M. Bray, A. E. Mazawi and R. G. Sultana (eds.). Private tutoring across the Mediterranean: Power dynamics and implications for learning and equity (pp. 151-165). Rotterdam: Sense Publishers.

MoNE (Ministry of National Education) (2010). Ortaögretim 2009 ÖBBS Raporu [Report on 2009 Assessment of Students Achievement in Secondary Education]. Ankara: Educational Research and Development Division.

MoNE (Ministry of National Education) (2011). National education statistics, formal education, 2010-2011. Ankara: Ministry of National Education. 
O’Brien, V., M. Martinez-Pons and M. Kopala (1999). Mathematics self-efficacy, ethnic identity, gender, and career interests related to mathematics and science. The Journal of Educational Research, 92(4), 231-235.

OECD (Organisation for Economic Co-Operation and Development) (2004). Learning for Tomorrow's World. Paris: OECD Publications.

OECD (Organisation for Economic Co-Operation and Development) (2011). Education at a Glance 2011: OECD Indicators, Paris: OECD Publishing.

Popa, S. (2007). Defensible spaces: Ideologies of professionalism and teacher's work in the Romanian private tutoring system. Unpublished doctoral dissertation, University of Pittsburgh, PA.

Stevens, J. (1992). Applied multivariate statistics for the social sciences. (2nd edn). Hillsdale: Lawrence Erlbaum Associates, Publishers.

Suryadarma, D., Suryahadi, A., Sumarto, S. \& Rogers, F. H. (2006). Improving student performance in public primary schools in developing countries: Evidence from Indonesia. Education Economics, 14(4), 401-429.

Tabachnick, G. B \& Fidell, S. N (1996) Using multivariate statistics (3rd edn). New York: Harper Collins College Publishing.

Tansel, A. (2013a). Supplementary education in Turkey: Recent developments and future prospects. In J. Aurini, S. Davies and J. Dierkes (eds), Out of the shadows? An Introduction to world-wide supplementary education. (pp. 23-66). International Perspectives on Education and Society series, vol. 22. Bingley, UK: Emerald.

Tansel, A. (2013b). Private tutoring and inequitable opportunities in Turkey: Challenges and policiy implications. In M. Bray, A. E. Mazawi and R. G. Sultana (eds.), Private tutoring across the Mediterranean: Power dynamics and implications for learning and equity (pp. 177-186). Rotterdam: Sense publishers.

Tansel, A \& Bircan, F. (2005). Effect of private tutoring on university entrance examination performance in Turkey. IZA Discussion Paper No: 1609. Bonn, Germany: Forschungsinstitut zur Zukunft der Arbeit/Institute for the Study of Labor (IZA).

Tansel, A. \& Bircan, F. (2006). Demand for education in Turkey: A tobit analysis of private tutoring expenditures. Economics of Education Review, 25(3), 303-313.

Tansel, A. \& F. Bircan (2008). Private supplementary tutoring in Turkey: Recent evidence on its various aspects. IZA Discussion Paper No: 3471. Bonn, Germany: Forschungsinstitut zur Zukunft der Arbeit/Institute for the Study of Labor (IZA).

TED (Turkish Educational Society) (2005). Turkiye'de Üniversiteye Giriş Sistemi Araştırması ve Çözüm Önerileri [An Investigation of the Universty Entrance System in Turkey and Proposals for Solution]. Ankara: TED Publication.

\section{The authors}

Giray Berberoğlu is a professor of Educational Measurement and Assessment at the Middle East Technical University (METU), Ankara. He received his BSc and MSc degrees from METU, and his PhD degree from Hacettepe University. He was a Fulbright visiting scholar in the academic years 1995-1996 and 2012-2013 at the University of Massachusetts, Amherst. He has worked as a consultant in national and international organisations and as a director of the Research and Development Section in Student Measurement and Selection Center (ÖSYM) inTurkey. His research agenda basically focuses on trends in students' learning, factors related to achievement in mathematics and natural sciences, and crosscultural and cross-lingual assessment of students. 
Aysit Tansel is a professor of Economics at the Middle East Technical University (METU), Ankara. She received her BSs from Middle East Technical University with high honors, her MA from University of Minnesota and her PhD from the State University of New York. She was a post-doctoral fellow at Yale University and a Fulbright fellow at Cornell University. She is a research fellow of the Institute for the Sutdy of Labor (Institut zur Zukunft der Arbeit; IZA) in Bonn, Germany and the Economic Research Forum (ERF) in Cairo, Egypt. She is a member of the editorial boards of numerous journals including Economics of Education Review, Equality Diversity and Inclusion, Turnalar Uluslararası Türk Dili Edebiyat ve Çeviri Dergisi and Iktisat Issletme ve Finans. 